\title{
Saccharification of Delignified Rice Straw by Fusarium oxysporum for Ethanol Production by Saccharomyces cerevisiae
}

\author{
Khadiga I.M. El-Gabry \\ Soil, Water and Environmental Research Institute, Agricultural Research Centre, Giza, \\ Egypt.
}

\begin{abstract}
TN THE PRESENT work, carrying out consolidated bioprocessing by mixed cultures of cellulytic fungus and yeast capable of fermenting hexoses was under scope. A preliminary test proved that there was no contradiction between using Saccharomyces cerevisiae as single culture or mixed with Fusarium oxysporum in fermenting glucose to ethanol. Rice Straw was subjected to delignification by alkaline/hypochlorite method. Delignified rice straw (RS) and carboxy methyl cellulose (CMC) individually were used in bioconversion process for ethanol production. Fusarium oxysporum performed fermentation with and without aeration, achieving ethanol production of $0.8 \mu \mathrm{l} / \mathrm{ml}$ and $2.9 \mu \mathrm{l} / \mathrm{ml}$, respectively, proving the importance of air absence in this process. The CMC and RS were applied in a submerged culture to give maximum cellulases activity of $0.444 \mathrm{U}$ and $1.474 \mathrm{U}$ after 8 days, respectively. In order to apply consolidated bioprocessing, saccharification of either CMC or RS by F. oxysporum was applied in a single submerged culture giving maximum saccharification efficiency of $16.8 \%$ and $16 \%$ after 7 and 11 days, respectively. In the same submerged culture, Saccharomyces cerevisiae was used to ferment the released sugar under no aeration achieving ethanol production of $6.1 \%$ and $3.878 \%(\mathrm{v} / \mathrm{v})$ corresponding to fermentation efficiency of $42.4 \%$ and $34.4 \%$, respectively. Keywords: Saccharification, Ethanol fermentation, Rice straw, CMC, Fusarium oxysporum, Saccharomyces cerevisiae.
\end{abstract}

\section{Introduction}

The key objective in any alcohol fermentation process is to reduce energy requirements and production costs. Cellulases production is an important step preceding production of ethanol in an economic process using any renewable cellulosic wastes (Mazharuddin khan et al., 2011). Rice (Oryza sativa) straw as an abundant agroresidue, has an approximate annual production of 731 million tons produced worldwide, from which around205 billion liters of bio-ethanol / year can be produced (Narra et al., 2012). Rice straw contains approximately 30-35\% cellulose, 25-30\% hemicellulose, 15-28\% lignin, and 4-7\% ashes. Cellulose and hemicellulose from these lingo-cellulosic materials are potent precursors for the second generation of biofuel. However, chemical fractionation and biological manipulation of these lingo-cellulosic materials are limited due to their complex matrix structure including their lignin content, acetylation and crystallinity (Sakdaronnarong and Jertjunya, 2012).

Therefore, an effective pretreatment for rice straw is required to remove lignin to efficiently increase cellulases access to cellulose. Beside acid and oxidative reagents, alkali pretreatment appears to be the most effective in breaking the ester bonds between lignin, hemicellulose and cellulose, as well as avoiding fragmentation of the hemicelluloses polymers (Narra et al., 2012). In this regard, Mohy et al. (2015) considered alkaline oxidation pretreatment as the most effective, simple and economic pretreatment. On this regard, they found that onehalf of lignin and most of hemicellulose content in rice straw was solubilized by alkaline hypochlorite pretreatment at room temperature after $24 \mathrm{~h}$. Added to that, crystallinity index decreased and consequently cellulose content increased in the pretreated biomass. After pretreatment, ethanol production requires different steps of hydrolysis (saccharification) and 
efficient ethanol recovery. Hydrolysis of biomass is essential for generation of fermentable sugars which are then converted to ethanol by microbial action (Sukumaran et al., 2009).

The degradation of cellulose to soluble sugars requires a cooperative action of number of enzymes together: endo-glucanases (EC 3.2.1.41), exo-glucanases (EC3.2.1.91) and $\beta$-glucosidases, collectively known as cellulases. Unlike cellulose (a linear glucose polymer), hemicelluloses are hetero polymers of a range of pentoses primarily xylose and arabinose, as well as hexoses such as galactose, mannose, other sugars and their uronic acids (Okeke and Obi, 1995; Sukumaran et al., 2009). Cellulase is produced via two methods: submerged liquid process and solid state process. Besides, most previous researches conducted cellulose hydrolysis in submerged process with many advantages regarding the process control (Shaibani et al., 2012). F. oxysporum probably more commonly known as a phyto-pathogen has the ability to produce a wide range of biomass degrading enzymes. It was found that $F$. oxysporum can generally use both hexoses and pentoses with the ability to ferment them to ethanol as had been discovered before (Christakopoulos et al., 1989; Singh et al., 1991; Zhou et al., 2002).

Hydrolysis and fermentation can be separately or simultaneously performed. In "Separate Hydrolysis and Fermentation" (SHF); hydrolysis and fermentation are applied sequentially in different bioreactors, while in "Simultaneous Saccharification andFermentation" (SSF); cellulose hydrolysis and hexose fermentation are applied simultaneously in the same bioreactor (Shaibani et al., 2012). Anasontzis and Christakopoulos (2014) stated that $F$. oxysporum was able to ferment monosaccharides to ethanol under anaerobic or micro-aerobic conditions. It bypasses the yeast by its ability to ferment pentoses, while yeast can ferment hexoses faster and better than fungi. In order to make $F$. oxysporum become advantageous in a realistic sense, a number of improvements must be done. This was why the present study was conducted to use this fungus individually in both cellulase production and saccharification of pretreated rice straw (RS), while studying its role in ethanol production with/without $S$. cerevisiae in a simultaneous action.

\section{Materials and Methods}

Rice straw was collected from a local farm in ElSharkia Governorate and cut into small fragments,

Env. Biodiv. Soil Security Vol.1 (2017) washed thoroughly and dried under vacuum at $60^{\circ} \mathrm{C}$ for 2 days. Pretreatments of rice straw by alkaline hypochlorite were carried out as described by Mohy et al. (2015). Ten grams of chopped rice straw were suspended in $200 \mathrm{ml}$ of $1.5 \% \mathrm{NaClO}$ at $\mathrm{pH} 11.5$ (0.3 g NaClO /g substrate) in a $500 \mathrm{ml}-$ conical flask, shacked overnight (100 rpm) at room temperature. Pretreated rice straw (RS) was filtrated and neutralized to $\mathrm{pH} 6.5-7.0$ by $1 \mathrm{~N} \mathrm{HCl}$, then thoroughly washed with distilled water and dried. $F$. oxysporum and $S$. cerevisiae were generously offered by Department of Microbiology, Soil, Water and Environment Research Institute. Starter cultures of $F$. oxysporum in PDA broth (Domsch et al., 1980) and $S$. cerevisiae culture in YM broth (Difico, 1985) were used.

On the other hand, modified Mandels medium was the basal medium used for enzyme production (Patel et al., 2007) in which 1\% carboxy methyl cellulose (CMC) or RS added as carbon sources and inoculated by $F$. oxysporum pre-culture (5\% $\mathrm{v} / \mathrm{v})$. The growth medium $\mathrm{pH}$ was adjusted at 5 , incubated at room temperature for required days under test on a rotary shaker at $125 \mathrm{rpm}$. The filtered broth was collected for determination of enzymatic activities (Roy et al., 1993). The enzymatic saccharification was started at $50^{\circ} \mathrm{C}$ in the same enzyme production broth for the required time under test.

The cellulases activity was estimated in terms of filter paper cellulases activity (FPase) using filter paper (Whatman, No.1) according to Ghose (1987). Glucose from produced after FPase action was measured with 3,5dinitrosalicilic acid reagent, according to Miller (1959). One unit of FPase activity (U) was defined as the amount of enzyme that can release $1 \mathrm{mg}$ reducing sugar as glucose per $1 \mathrm{hr}$, under assay conditions, in $1 \mathrm{ml}$ reaction mixture. Saccharification efficiency \% was calculated according to Gould (1984). Pure glucose was used as the sole carbon source at a concentration of $10 \%(\mathrm{w} / \mathrm{v})$ in the modified Mandels medium in narrow necked bottles for testing fermentation by single and mixed cultures of $F$. oxysporum and $S$. cerevisiae. Bottles were kept stagnant during fermentation at room temperature.

Cotton plugged bottles were filled to half of its volume with Mandel's medium with either RS or $\mathrm{CMC}$ and were shaken at $120 \mathrm{rpm}$ then incubated at $35^{\circ} \mathrm{C}$ to ensure cellulases production by the fungal inoculum during a saccharification period of 2 days. The same bottles were completed up to three fourths of their volumes with sterile 
fermentation medium to minimize air volume. In such fermentation tests, two methods were applied to control aeration conditions. Bottles were either cotton plugged (aeration) or firmly caped (no aeration) with stoppers and in both cases the same individual fungi, which was responsible for saccharification allowed to ferment the released sugars.

Spectrophotometric determination of ethanol was carried out according to Caputi et al. (1968), where ethanol was expressed as $\mu \mathrm{l}$ ethanol $/ \mathrm{ml}$. The Fermentation medium based on the modified medium recommended by Sarabana et al. (2015) was employed. Starter cultures from $F$. oxysporum and $S$. cerevisiae were adjusted to a fixed dry biomass $\%(w / v)$ and used for inoculation of the fermentation medium so that the inoculant volume didn't exceed 10\% v/v (Kenealy and Dietrich, 2004). The fermentation medium volume was either $100 \mathrm{ml}$ in $250 \mathrm{ml}$ conical flasks to ensure best aeration, or $150 \mathrm{ml}$ enclosed in $200 \mathrm{ml}$ firmly closed bottles to maintain minimized air condition for fermentation process. Saccharified RS or $\mathrm{CMC}$ by fungi was introduced to fermentation by either yeast or fungi without sterilization to fulfill consolidated bioprocessing fundamental.

Calculations (Mohy et al., 2015):

Saccharification degree $(\%)=\frac{R(m g) \times 100}{C(m g) \times 0.9}$

Ethanol fermentation efficiency $\%=\frac{\text { ethanol actual yield } \times 100}{\text { ethanol theoretical yield }}$ where; Ethanol theoretical yield \% from hexoses $=51.2 \%$.

where; R: total released reducing sugar, $\mathrm{C}$ : Total carbohydrates in the substrate (RS)

Data were statistically analyzed for the least significant differences (LSD) adopting the procedure mentioned by Gomez and Gomez (1984).

\section{Results and Discussion}

Fermentative performance in single or mixed cultures by F. oxysporum and $S$. cerevisiae

The performance of yeast under minimum aeration wasn't affected when the yeast strain was grown in pure or in a mixed culture, giving $8.867 \mu \mathrm{l} / \mathrm{ml}$ and $7.870 \mu \mathrm{l} / \mathrm{ml}$, respectively (Figure 1). In both cultures, maximum ethanol production after 12 hour ranged from 7.8 to $8.9 \mu \mathrm{l} / \mathrm{ml}$, statistically considered convergent performance, indicating the absence of antagonism between the two strains. Growing $F$. oxysporum in a pure single culture resulted in lower ethanol production with a maximum production of $3.7 \mu \mathrm{l} / \mathrm{ml}$ after 48 hours. The actual fermentation efficiency by yeast in a mixed or single culture achieved nearly 12.2 to $13.7 \%$ of the theoretical efficiency in the first 12 hours. Depending on this finding, the unfermented glucose mostly played as a carbon source for yeast metabolism.

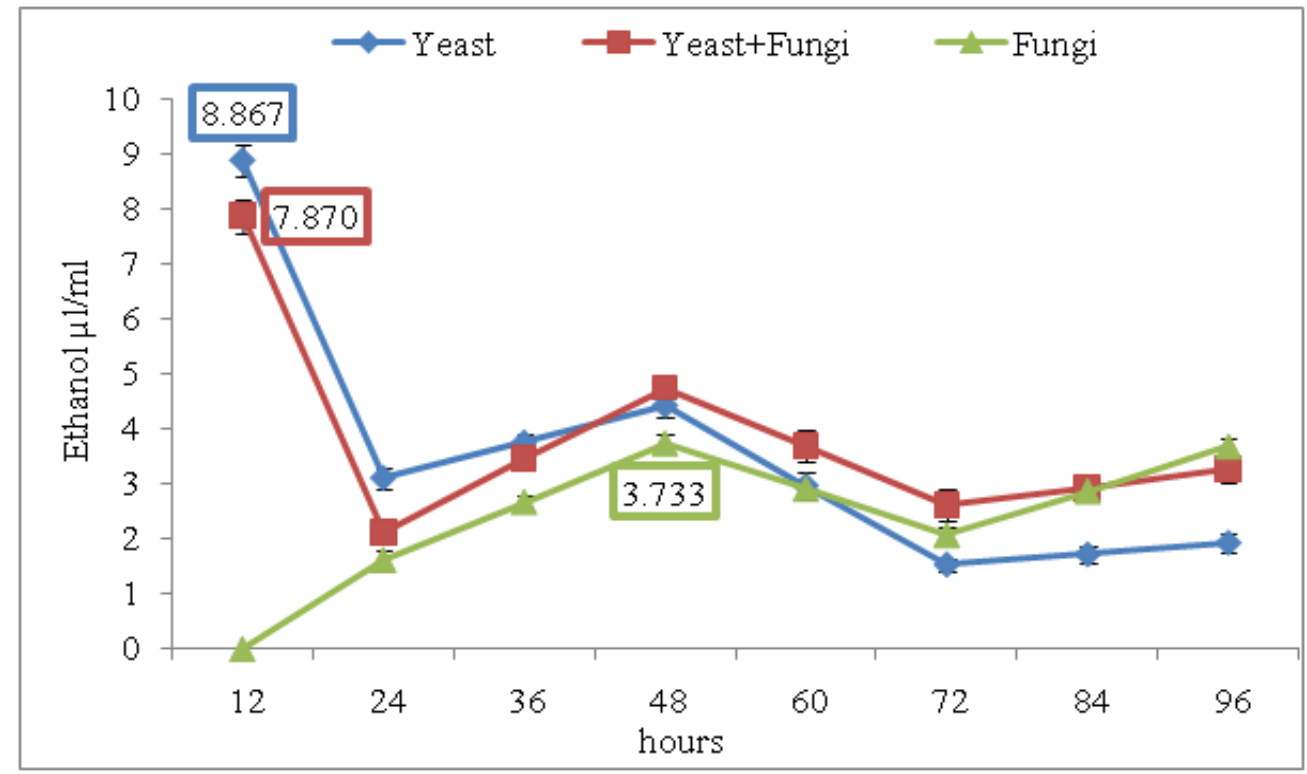

Fig. 1. Ethanol production from $10 \%$ glucose by $F$. oxysporum and $S$. cerevisiae, either in pure or as mixed cultures, under minimum aeration $(\mathrm{LSD}=\mathbf{0 . 3 2 2})$. 
Previous reports by Dashko et al. (2014) referred to the ability of the yeast Saccharomyces cerevisiae to thrive and ferment sugars under either aerobic or anaerobic conditions. However, the yeast performance varies according to aeration magnitude which emphasizes in the present work the drop in fermentation efficiency down to $13.5 \%$ than in ideal anaerobic conditions. Alam et al. (2007) tested the possibility of ethanol production in presence of both cellulytic fungi and fermentative yeast. They found that combination of $S$. cerevisiae, Phanerochaete chrysosporium, Trichoderma harzianum was compatible and able to produce ethanol through utilizing rice straw in a direct bioconversion process with high efficiency than single cultures. This finding meets with the absence of antagonism between $S$. cerevisiae and F. oxysporum in the present work.

Effect of aeration on ethanol production by $F$. oxysporum grown on CMC and RS

$F$. oxysporum was grown on either CMC or $\mathrm{RS}$ at $35^{\circ} \mathrm{C}$ during the first two days to encourage cellulases production and saccharification of either substrates, after which the fermentation process began under controlled conditions as suggested before, through which ethanol was produced as shown in figures (2; a and b). The results suggested that turning aeration conditions to its minimum pushed the fungi to ferment available fermentable sugars parallel to a prolonged cellulytic action and glucose production from the substrate during 13 day fermentation period. In such a mixed process, ethanol quantity increased cumulatively during almost all the fermentation periods, which dropped after words which might be due to ethanol consumption by the fungus itself as suggested by El-Gabry et al. (2016).

On the other hand, the CMC mostly induced endo-cellulases production in the first 2 days with less efficiency in releasing reducing sugars if compared with the RS which mostly induced production of all cellulase types (endo-cellulases, exo-cellulases and $\beta$-glucosidases) due to their collective synergistic effect (Mohy, 2017). In spite of many possible inhibitory compounds including phenolic compounds and furan aldehydes that might have been formed during alkaline oxidative pretreatment of rice straw (Jönsson, and Martin, 2016) but there was no retardation in ethanol maximum production than with CMC. These findings affected indirectly the reducing sugar available for fermentation. Ethanol produced from saccharified RS was more than that when saccharified CMC was used, as in the aerated and non-aerated conditions the fungi gave $1.4 \mu \mathrm{l} / \mathrm{ml}$ and $2.85 \mu \mathrm{l} / \mathrm{ml}$ with $\mathrm{RS}$, respectively. This might be due to the fungal ability to ferment pentoses released from saccharified RS after finishing fermentation of hexoses in the same source (Anasontzis and Christakopoulos, 2014). That was obvious from the semi stable level of ethanol produced during non-aerated fermentation of both saccharified CMC and RS after 6 days.

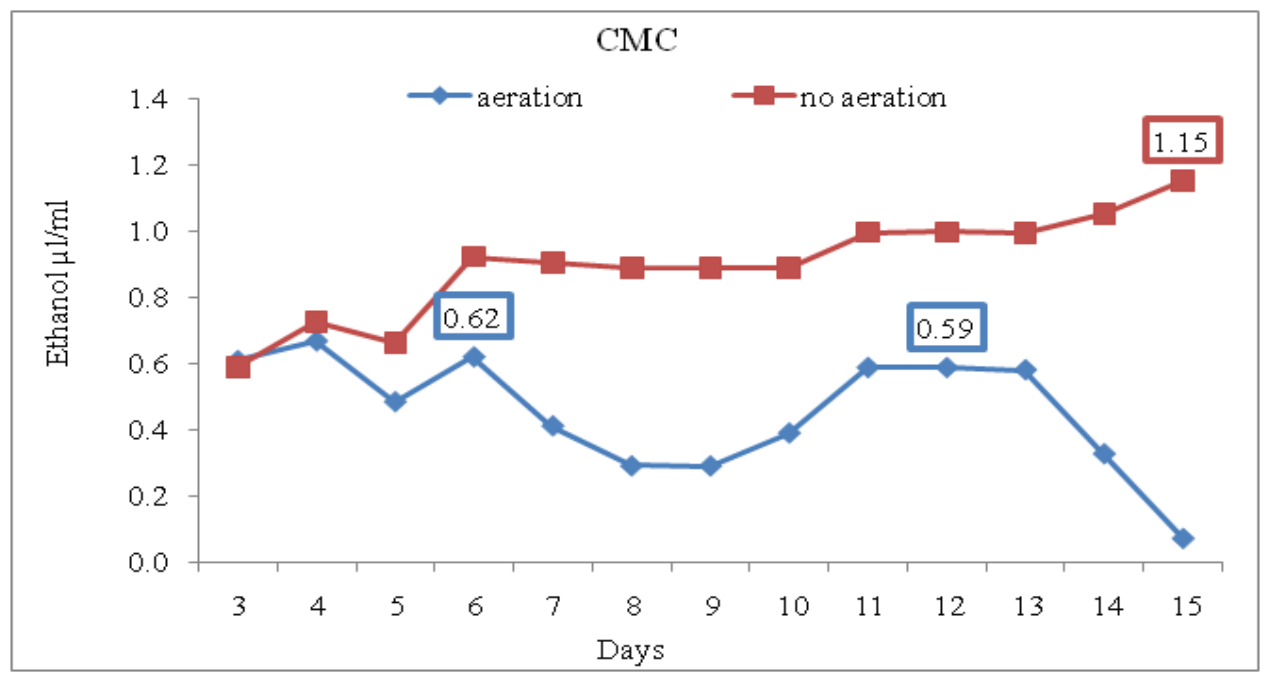

Fig. 2a. Ethanol production by $F$. oxysporum on saccharified CMC under aeration and no aeration conditions(LSD= 0.096).

Env. Biodiv. Soil Security Vol.1 (2017) 


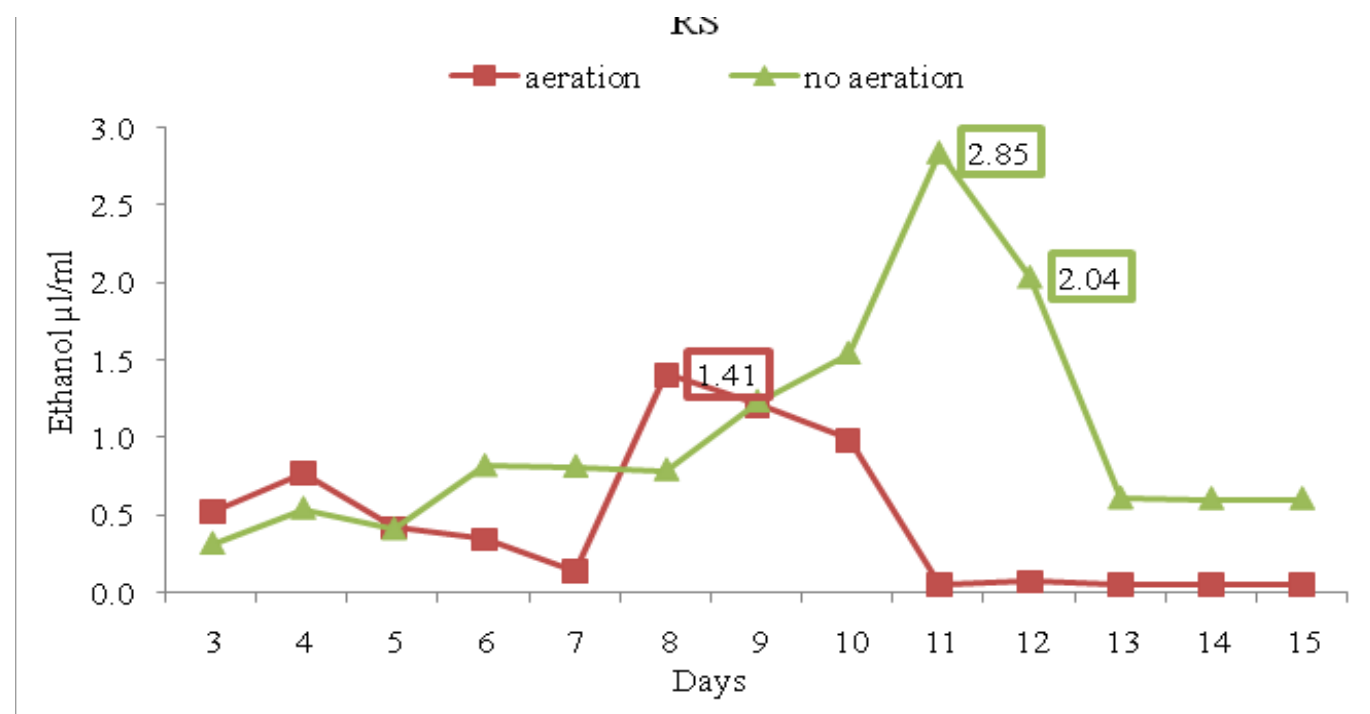

Fig.2 b. Ethanol production by $F$. oxysporum on saccharified RS under aeration and no aeration conditions (LSD $0.05=0.234)$.

Ethanol production from saccharified CMC and $R S$ in single and mixed cultures of F. oxysporum and $S$. cerevisiae under no aeration

It appeared clearly that in case of CMC, the fungi responsible for producing cellulases used for saccharifying the CMC was negatively affected by saccharification temperature at $50^{\circ} \mathrm{C}$ (Fig. 3; a and b) which was obvious when additional fungal inoculum was added leading to elevated fermentation capability. This correlation was reversed in case of $\mathrm{RS}$, as increasing fungal inoculum might had consumed sugars from saccharified $\mathrm{RS}$ in growth more than in fermentation and ethanol production, as it was previously noted by Sarbana et al. (2015) and El-Gabry et al. (2016). As it was explained that the presence of yeast extract as nitrogen source served as electron acceptor that compensate the scarcity of oxygen in minimum aeration leading to its growth over the expense of fermenting sugar to ethanol. Besides, this lights out the importance of fungal inoculum size ratio to available fermentable sugars. As this ratio increased, sugar portion mainly consumed in growth and vice versa. Moreover, the fungal cells responsible for cellulase production that was subjected to higher temperature $\left(50^{\circ} \mathrm{C}\right)$ during saccharification was pushed to form more spores, which in turn regenerated faster with possibly more vital conditions at $35^{\circ} \mathrm{C}$ than the vegetative form as stated before by Patel et al. (2007), and in turn fermenting the sugars more efficiently, specially any possible pentoses, at day 3 .
With CMC the fungal existence alone during the 5 days of fermentation allowed two parallel processes to take place. Mainly fermenting sugar resulted from previous saccharification process and very possible prolonged cellulytic action (mostly endo $\beta$ 1,4 glucanase) and saccharification under $35^{\circ} \mathrm{C}$ allowing increase in sugar content leading to final increase in ethanol up to $2 \mathrm{ml} / \mathrm{ml}$. The existence of yeast with fungi took advantage of this phenomenon as ethanol produced was much than that by yeast alone.

Successive consolidated bioprocessing for ethanol production by fungi

This experment was classified into three stages. At the first stage, F.oxysporum was grown at $35^{\circ} \mathrm{C}$ for 13 days on either CMC or RS $(10 \%)$ as a sole carbon source for cellulases production. FPase was measured through the 13 days with occasional addition of $\mathrm{N}$ source every 5 days. Highst cellulases activity was $0.444 \mathrm{U}$ and 1.474 $\mathrm{U}$, achieved at $8^{\text {th }}$ when the fungus was grown on the CMC and RS, respectively. Depending on those results, the previous experiment was repeated up till the $8^{\text {th }}$ day to ensure maximum cellulases production on $35^{\circ} \mathrm{C}$, after which the temperature was shifted up to be $50^{\circ} \mathrm{C}$ for applying efficient saccharification up till the $11^{\text {th }}$ day. Worthy to mention that cellulases production was done distributed in 33 fermentation bottles to ensure sampling every day in triplicate individual bottles for either $\mathrm{CMC}$ or RS. The maximum released sugar measured was at the $7^{\text {th }}$ and $11^{\text {th }}$ days when the fungus was grown on CMC and RS recording Env. Biodiv. Soil Security Vol.1 (2017) 
$1.44 \%$ and $1.13 \%(\mathrm{w} / \mathrm{v})$, nearly corresponding to saccharification degree of $15.98 \%$ and $16.74 \%$, as shown in Figures (4-b) and (5-b), respectively. The very slow increase in release of reducing sugars of saccharification may be primarily due to end-product inhibition and to some extent thermal instability during the long reaction period, as mentioned before by Okeke and Obi (1995).

All saccharified CMC and RS bottles were consequently inoculated with $S$. cerevisiae and more fermentation medium was added to minimize void volume for less aeration. The highest ethanol production was achieved at the $7^{\text {th }}$ and the $11^{\text {th }}$ day, recording $0.605 \%$ and $0.388 \%(\mathrm{v} / \mathrm{v})$, for $\mathrm{CMC}$ and $\mathrm{RS}$, corresponding to fermentation efficiency of 95.6 and $78.2 \%$, as shown in Figures (4-c) and (4-c), respectively. Compared to the work of Sukomara et al. (2009), they found that highest yield of reducing sugars was $26.3 \mathrm{~g} / \mathrm{L}$ obtained from enzymatic hydrolysate of rice straw while in the present work it reached $11.3 \mathrm{~g} / \mathrm{L}$. When they used it as substrate for ethanol production by $S$. cerevisiae, the ethanol yield was $0.09 \mathrm{~g} / \mathrm{g}$ pretreated rice straw while it was nearly $0.05 \mathrm{~g} / \mathrm{g}$ pretreated rice straw in the present work.

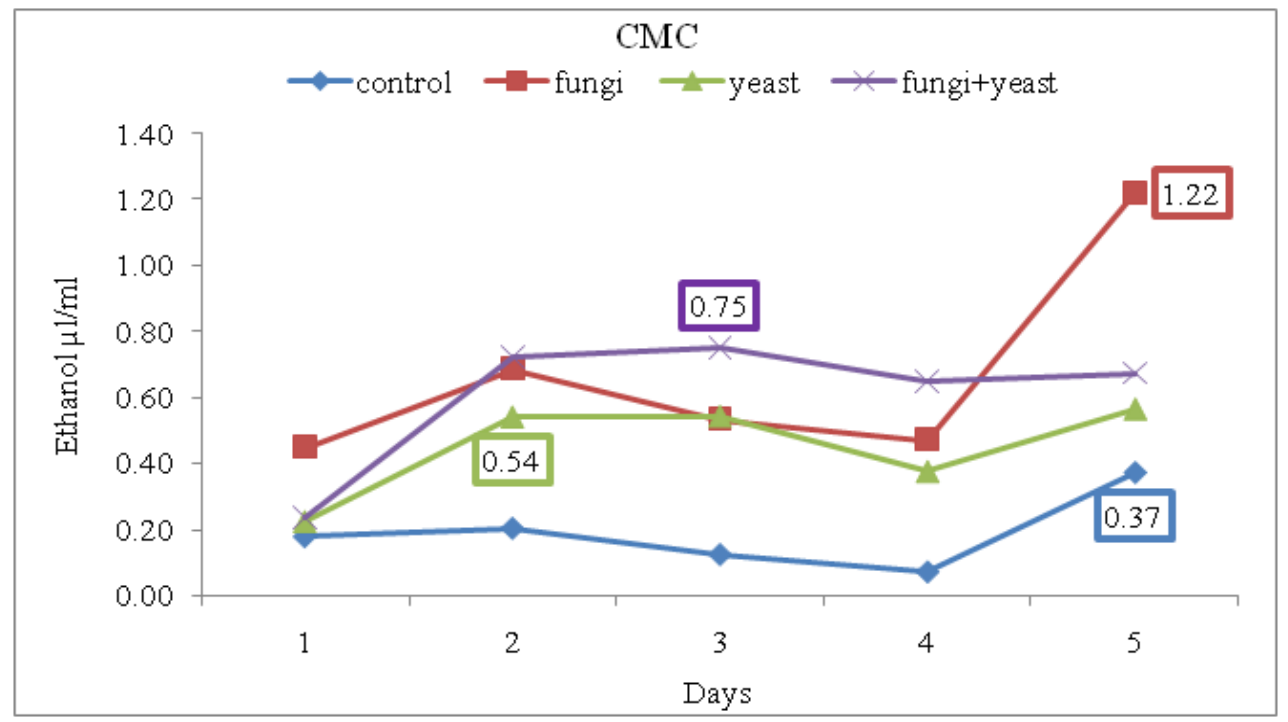

Fig. 3a. Ethanol production from saccharified CMC by $F$. oxysporum and $S$. cerevisiae inoculums applied individually or as mixed culture under no aeration (LSD $0.05=0.116$ ).

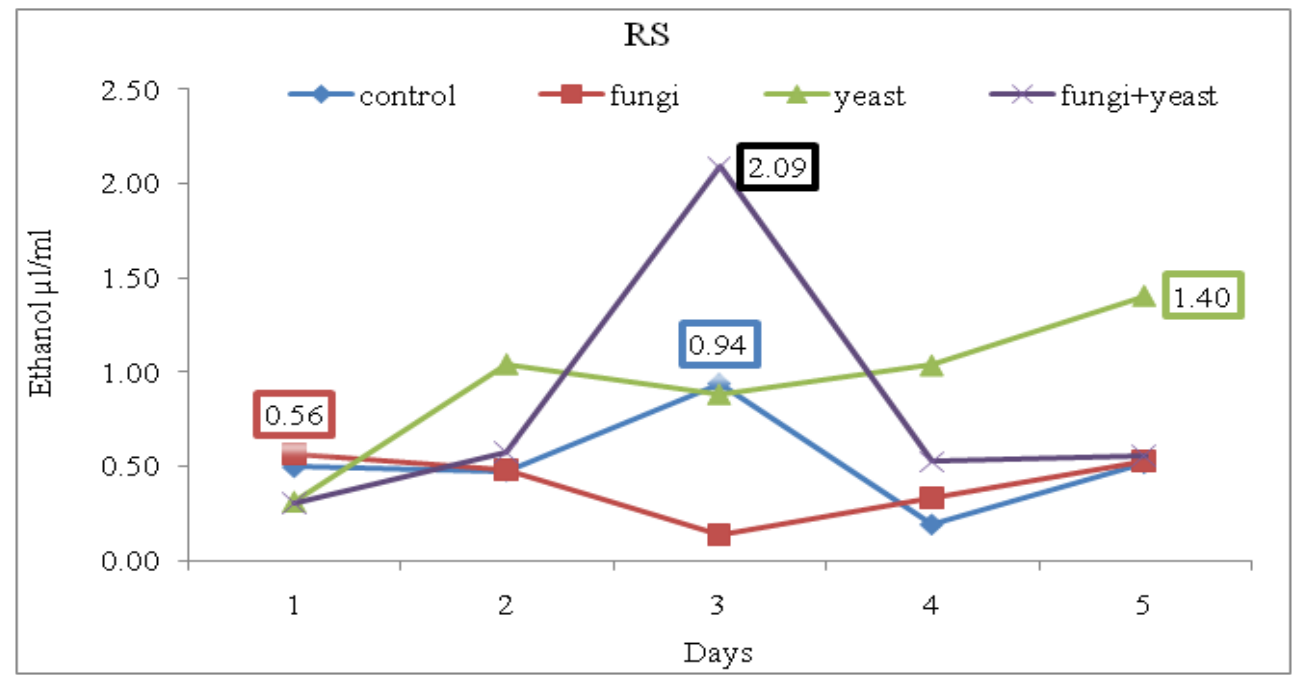

Fig. 3b. Ethanol production from saccharified RS by $F$. oxysporum and $S$. cerevisiae inoculums applied individually or as mixed culture under no aeration(LSD $0.05=\mathbf{0 . 2 5 6})$.

Env. Biodiv. Soil Security Vol.1 (2017) 

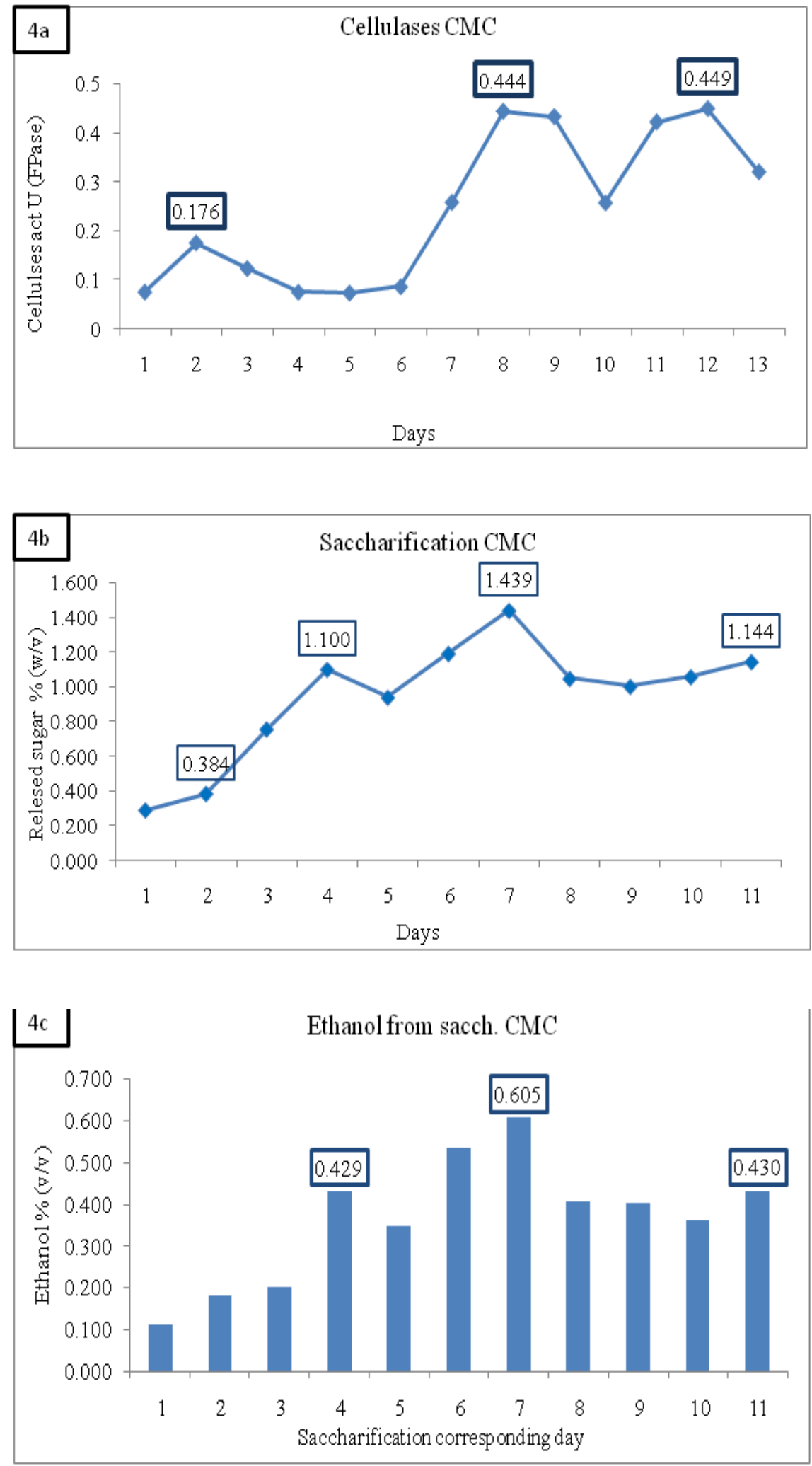

Fig. 4. a- Cellulases production (LSD $0.05=0.138)$, b- Saccharification of CMC (LSD 0.05 = 11.99) and c- Ethanol production on saccharified CMCunder minimum aeration condition (LSD $0.05=0.052$ ) by $F$. oxysporum. 

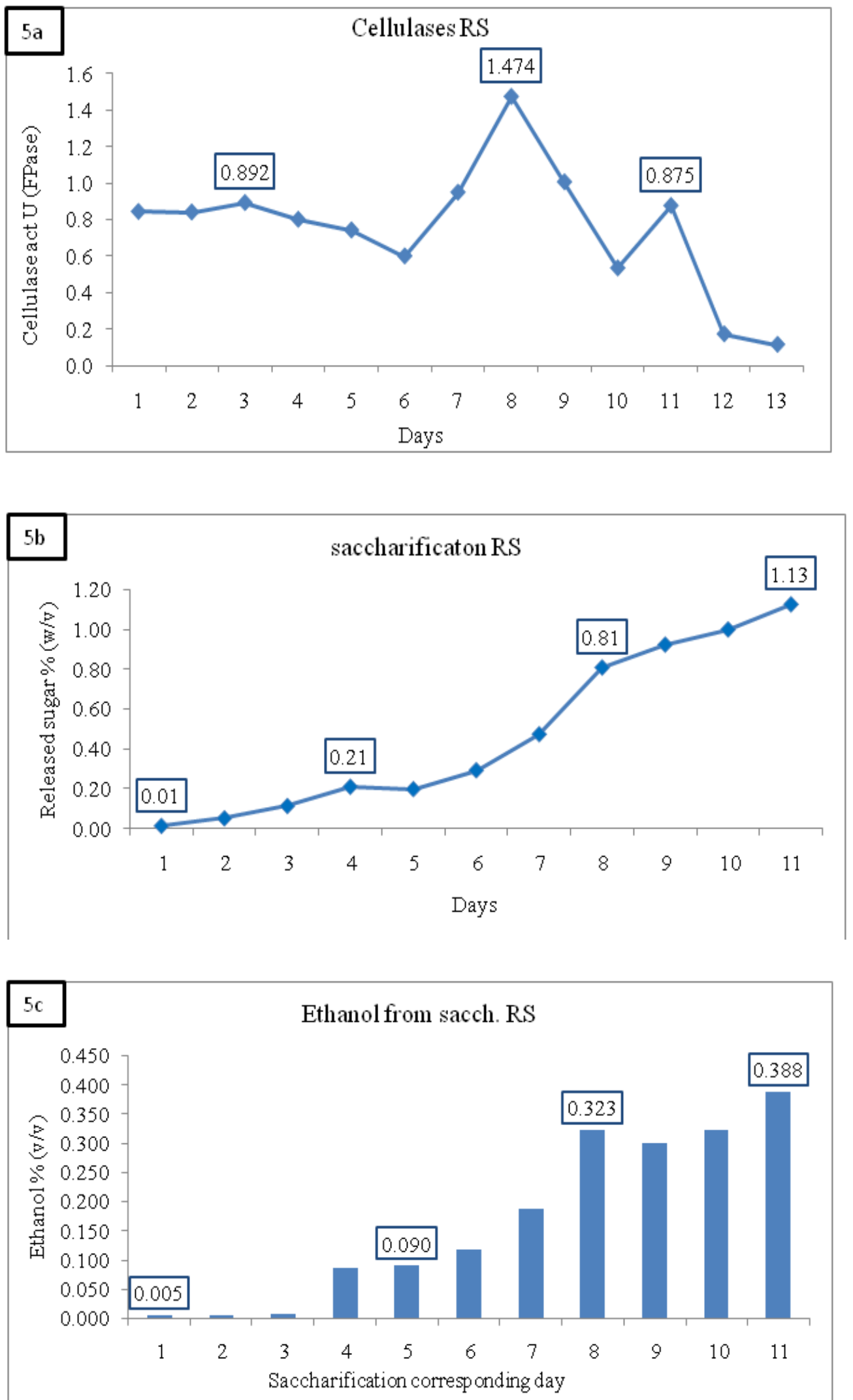

Fig. 5. a- Cellulases production (LSD $0.05=0.33$ ), b- Saccharification of RS (LSD $0.05=8.133$ ) and c- Ethanol production on saccharified RS under minimum aeration condition(LSD $0.05=0.34$ )by $F$. oxysporum.

Env. Biodiv. Soil Security Vol.1 (2017) 
On the other hand, Vintila et al. (2009) used cellulases produced by Trichoderma viride CMIT3.5 together with $S$. cervisiae CMIT2.18 in applied simultaneous hydrolysis and fermentation of lignocellulose at the temperature of $40^{\circ} \mathrm{C}$. This system can lower the price of ethanol produced from lingo cellulosic biomass. Also, Vintilai et al. (2011) found that the yeasts and cellulases can work in the same medium and at common parameters. Although common yeasts are able to ferment glucose and produce ethanol at $30-35^{\circ} \mathrm{C}$ and cellulases have the optimal activity at $50^{\circ} \mathrm{C}$, certain yeast strains and cellulases can act together at common temperatures of $37-40^{\circ} \mathrm{C}$ and in the same medium. Then the previously mentioned $S$. cerevisiae CMIT2.18 can be successfully used to ferment glucose produced by cellulases in the same medium, at temperatures of $37-40^{\circ} \mathrm{C}$ in simultaneous saccharification and fermentation (SSF) process to convert lingo cellulosic biomass to ethanol.

Pasha et al. (2012) studied sequential cellulase production, saccharification and ethanol production experiment in a set, where Aspergillus niger which had been responsible for cellulase production was inactivated by autoclaving after saccharification. They found that the maximum fermentation efficiency by yeast was observed as maximum of sugars were utilized for ethanol production. Whereas in non-autoclaved set after saccharification, less fermentation efficiency was noted, as some of released sugars must have been utilized by $A$. niger, hence ethanol conversion by yeast was reduced. This observation was crucial in explaining the low fermentation efficiency of $78.2 \%$ compared to the theoretical efficiency.

\section{Conclusion}

From the foregoing results, it could be concluded that $F$. oxysporum achievement with CMC was more successful than with RS as it released more glucose during saccharification. It might be correlated to the type of substrate that induced the $F$. oxysporum to release the corresponding type of cellulases, as CMC is well known as a specific substrate and inducer for $\beta$ 1,4 endoglucanase. On the other hand, RS that needs more cellulases types including endo and exocellulases beside $\beta$ - glucosidases. Add to that, the complex and crystalline structure of cellulose forming $\mathrm{RS}$ than that in $\mathrm{CMC}$ beside the presence of residual lignin and ash acting as inhibitors (Mohkami and Talaeipour, 2011; Mohy et al., 2015). Never the less, fermentation efficiency of sugar released from saccharified RS and CMC by
$S$. cervisiae in presence of $F$. oxysporum wasn't relevant to glucose quantity, as saccharified RS negatively affected $S$. cervisiae performance that might be correlated to the presence of residual lignin in RS predicted to be $8 \%$ and ash too (Mohy et al., 2015), while it was absent in CMC. According to the obtained results, the present study established the possibility of using $F$. oxysporum on pretreated RS for the production of fermentable sugars with acceptable efficiency which can be further utilized for production of biofuel and other valuable commodities via industrial fermentation.

\section{References}

Alam, M. Z.; Kabbashi, N. A. and Ismail, M. H. (2007). Direct Bioconversion of agricultural waste-rice straw into bioethanol. J. Env. R. and Develop., 2(2):118-125.

Anasontzis, G.E. and Christakopoulos, P. (2014). Challenges in ethanol production with Fusarium oxysporum through consolidated bioprocessing. Bioengin., 5(6):1-3.

Caputi, A. Jr.; Ueda, M. and Brown, T. (1968). Spectrophotometric determination of ethanol in wine. Am. J. Enol. Vitic., 19(3):160-165.

Christakopoulos, P.; Macris, B. J. and Kekos, D. (1989). Direct fermentation of cellulose to ethanol by Fusarium oxysporum. Enzyme Microb. Technol., 11:236-9; http://dx.doi.org/10.1016/0141-0229 (89)90098-7 [Cross Ref].

Dashko, Sofia; Nerve, Z.; Compagno, C. and Piškur J. (2014). Why when, and how did yeast evolve alcoholic fermentation? FEMS Yeast Res, 14 (6) 826-832.

Domsch, K.H.; Gams, Anderson W. and Traute-Heidi, (1980). Compendium of Soil Fungi, 1:78-89.

El-Gabry, Khadiga I. M.; Mohy, E. A. and Sarabana, Sanaa H. (2016). Optimizing growth conditions provoked ethanol production by fungi grown on fructose. Middle East Journal of App. Sci., 6 (3):479-489.

Ghose, T.K. (1987). The measurement of cellulase activities. Pure Applied Chem., 59 (2):257-268.

Gomez, K. A. and Gomez, A.A. (1984). Statistical Procedures for Agricultural Research, $\left(2^{\text {nd }} \mathrm{Ed}\right), \mathrm{pp}$ : 20-29 and 359387.

Gould, J. M. (1984). Alkaline peroxide delignification of agricultural residues to enhance enzymatic saccharification..Biotechnol. Bioeng., 24:46-52.

Jönsson L. J. and Martin C. (2016). Pretreatment of lignocellulose: Formation of inhibitory by-products and strategies for minimizing their effects. Biore. Tech., 199:103-112.

Env. Biodiv. Soil Security Vol.1 (2017) 
Kenealy, W.R. and Dietrich, D.M. (2004). Growth and fermentation responses of Phanerochaete chrysosporium to $\mathrm{O}_{2}$ limitation. Enz. Microb. Tech., 34:490-498.

Mazharuddin khan, M.; Munawer khan, M. and Mir, N. A. (2011). Production of ethanol by submerged fermentation from cellulosic substrates by Saccharomyces cerevisiae. Biotechnol. Bioinf. Bioeng, 1(2):183-186.

Miller, G. L. (1959). Use of dinitrosalicylic reagent for determination of reducing sugar. Anal. Chem., 31:426-428.

Mohkami, M. and Talaeipour, M. (2011). Investigation of the chemical structure of carboxylated and carboxymethylated fibers from waste paper via XRD and FTIR analysis. Journal Bioresources, 2(6): 1988-2003.

Mohy, E.A. (2017). Synergistic saccharification by mixture of several fungal semi purified cellulose degrading enzymes. Middle East J. of App. Sci., 7 (1):110 - 125 .

Mohy, E.A.; Dokhan, M. A.; Swelim, A. M. and Mohamed, Amina M. (2015). Enhanced enzymatic sacchrification of rice straw and sugar cane bagasse by Trichoderma ressei Atcc 26921 cellulases. Biological Chemistry and Envi. Sci., 10(1):531-548.

Narra, M.; Dixit, G.; Divecha, J.; Madamwar, D. and Shah, A. R. (2012). Production of cellulases by solid state fermentation with Aspergillus aterreus and enzymatic hydrolysis of mild alkalitreated rice straw. Biore. Tech., 121:355-361.

Okeke, B. C. and Obi, S. K. C. (1995). Saccharification of agro-waste materials by fungal cellulases and hemicellulases. Bioresorse Tech., 51: 23-27.

Pasha, C.; Sekhar, B. C.; Srinivas, B.; Balakrishna, K. and Hanumalal, N. (2012) Sequential cellulose production, saccharification and ethanol fermentation using rice straw. J. of Scientific and Industrial Research, 71:616-620.

Patel, S. J.; Onkarappa, R. and Shobha, K. S. (2007). Study of ethanol production from fungal pretreated wheat and rice straw. The Internet J. Microbiol., 4(1):575-583.

Roy, P.K.; Roy, U. and Vora, V. (1993). Hydrolysis of wheat, rice bran and jute powder by immobilized enzymes from Macrophominaphascolina. World J. of Microbiol. and Biotechnol., 2:102-106.

Sakdaronnarong C. and W. J. lertjunya. (2012). Rice straw and sugarcane bagasse degradation mimicking ligno cellulose decayin nature: An alternative approachto biorefinery. Science Asia, 38:364-372.

Env. Biodiv. Soil Security Vol.1 (2017)
Sarabana, Sanaa H.; El-Gabry, Khadiga I. and Mohy, A. (2015). Optimizing growth conditions provoked ethanol production by fungi grown on glucose. $M$. E. J. App. Sci., 5(4):1222-1231.

Shaibani, N.; Yaghmaei, S.; Andalibi, M. R. and Ghazvini, S. (2012). Ethanol production from sugarcane bagasse by means of on-site produced and commercial enzymes; a comparative study. Chem. Eng., 5(6)2:91-96.

Singh, A. and Kumar, P.K.(1991). Fusarium oxysporum: status in bioethanol production. Crit Rev Biotechnol, 11:129-47; PMID: 1913845. http://dx.doi.org/10.3109/07388559109040619 [PubMed] [Cross Ref]

Sukumaran, R. K.; Singhania, R.; Mathew, G. M. and Pandey, A. (2009). Cellulase production using biomass feed stock and its application in lignocellulose saccharification for bio-ethanol production. Renewable Energy, 34: 421-424.

Vintila, T.; Dragomirescu, M.; Jurcoane, M. S.; Vintila, D.; Caprita, R. and Maniu, M. (2009). Production of cellulase by submerged and solid-state cultures and yeasts selection for conversion of lignocellulose to ethanol. Romanian Biotechnological Letters, 14,(2):4275-4281.

Vintilai, T.; Vintilai, D.; Neoi, S.; Tulcani, C. and Hadaruga, N. (2011). Simultaneous hydrolysis and fermentation of lignocellulose versus separated hydrolysis and fermentation for ethanol production. Romanian Biotechnological Letters, 16(1):106-112.

Zhou, Z.; Naoki, T.; Akira, N.; Masashi, Y.; Kanji T. and Hirofumi S. (2002). Ammonia fermentation, a novel anoxic metabolism of nitrate by fungi. The Journal of Biological Chemistry, 227(3): 892-1896.

(Received 17/11/2017; accepted 11/12/2017) 